\title{
Frege on the Generality of Logical Laws
}

\author{
(Forthcoming: European Journal of Philosophy)
}

\begin{abstract}
Frege claims that the laws of logic are characterized by their "generality," but it is hard to see how this could identify a special feature of those laws. I argue that we must understand this talk of generality in normative terms, but that what Frege says provides a normative demarcation of the logical laws only once we connect it with his thinking about truth and science. He means to be identifying the laws of logic as those that appear in every one of the scientific systems whose construction is the ultimate aim of science, and in which all truths have a place. Though an account of logic in terms of scientific systems might seem hopelessly antiquated, I argue that it is not: a basically Fregean account of the nature of logic still looks quite promising.
\end{abstract}

\section{A Normative Science}

Does logic study how thinkers ought to think, or how they do, in fact, think? Is it the "ethics" or the "physics" of thinking? These were the terms in which the nature of logic was being disputed when Frege came to formulate his own mature views about it. ${ }^{1} \mathrm{He}$ affirms that "like ethics, logic can also be called a normative science," (Frege 1897a, 128) and diagnoses a confusion that leads people to mistakenly take up the opposing position. It is "commonly granted that the logical laws are guidelines which thought should follow" but "it is only too easily forgotten," (Frege 1893, xv) because, though we correctly "define the task of logic as the investigation of the laws of thought," (Frege 1879-1891, 4) we become confused by "the ambiguity of the word 'law'...In one sense [a law] says what is; in the other it prescribes what ought to be" (Frege 1893, xv). By applying the

\footnotetext{
${ }^{1}$ For a discussion of the state of the debate at the time, see Chapter 1 of Carl 1994.
} 
wrong sense in the claim that logic investigates the laws of thought, we wrongly conclude that logic studies "laws in accordance with which thinking actually takes place" (Frege 1879-1891, 4).

Frege thinks that what makes the error particularly hard to avoid is that the laws of logic are actually laws in both senses: they both assert what is and prescribe what ought to be. As statements of what is, however, they have no special relationship to thought: they tell us, for example, that everything is self-identical. But by stating what is, they also tell us how we ought to think, because "any law asserting what is, can be conceived as prescribing that one ought to think in conformity with it, and is thus in that sense a law of thought." This way of being a law of thought, Frege notices, "holds for geometrical and physical laws no less than for the logical” (Frege 1893, xv).

But if every law is a law of thought, then Frege cannot define the task of logic as the investigation of the laws of thought. He holds onto something close to that definition by claiming that the laws of logic are those with a special claim to being laws of thought, because "they are the most general laws, prescribing how to think wherever there is thinking at all" (Frege 1893, xv). Hence, "the task we assign logic is only that of saying what holds with the utmost generality for all thinking, whatever its subject matter." (Frege 1897a, 128). The laws of logic are distinctive laws of thought, because they are the most general.

What exactly does this "generality" amount to? One might assume that he is saying that the logical laws tell us about everything there is: they are universal generalizations. But that kind of generality is not special. On Frege's analysis, a law like "All whales are mammals" is a universal generalization, saying that every object is such that if it is a whale, it is a mammal. One might point out that the laws of other sciences are often, in a sense, "restricted" by their conditional form: the above law is in this sense "restricted to 
whales." But many of Frege's logical laws have this conditional form too. (For example, Basic Law I says something like "For all objects $\mathrm{x}$ and $\mathrm{y}$, if $\mathrm{x}$ is the True then if $\mathrm{y}$ is the True then $\mathrm{x}$ is the True.") One might point out that many logical laws involve higher-order generality as well as first-order generality: they tell us about all concepts (or properties) as well as all objects. But not all logical laws involve second-order generality. (Again, Basic Law I does not.) $)^{2}$ What Frege is saying, then, is not about the appearance of the concept of generality in the laws. So what is he saying?

As I will argue, we do not yet have an adequate answer to this question. This strikes me as a scandal. Until we know what Frege thinks logical truths are, we do not know how Frege understood the central claim of his work, that arithmetical truths are logical truths. Nor can we understand what he took himself to be doing when he put forward the logical system whose essentials we still teach every undergraduate philosophy major today. This is why it matters what, on his mature view, Frege thinks logic is, and most of this paper is dedicated to answering that question. In the final section, I will discuss why it matters what logic really is, and argue that though accounts in the spirit of Frege's view are currently neglected, we should take them seriously.

Since it is his mature views that concern us, and since there is a real possibility that he changed his mind over time, we will focus, at least at first, only on the key passages in his Basic Laws of Arithmetic and other work from around the same time. ${ }^{3}$ Once we have in this way arrived at basic constraints that any interpretation must satisfy, we can bring in what he says elsewhere, when doing so helps to fill out an interpretation that

\footnotetext{
${ }^{2}$ Macbeth 2005 (103-108) argues that the logicality of Basic Law I and the other laws that lack secondlevel generality depends on the fact that it "can be construed" so that it involves multiple levels of generality. But any law can be "construed," along the lines she suggests, and she offers no reason to think Frege attaches any importance to the possibility of reconstruals of his logical laws.

${ }^{3}$ To arrive at the two criteria of adequacy mentioned in section 5, I rely only on Frege's work from 1893 and 1897, and very occasionally on a paper that may have been written in 1891. See Linnebo 2003, Mezzadri 2018, and the discussion in section 5 below for reasons to think that Frege changes his mind about central aspects of logic.
} 
satisfies those constraints.

\section{Generality: The Required Vocabulary Interpretation}

Frege thinks that "logic...has its own concepts and relations...To logic, for example, there belong the following: negation, identity, subsumption, subordination of concepts...' (Frege 1906b, 338). Thomas Ricketts has suggested that the generality of the logical laws is inherited from special features of the vocabulary that refers to these concepts and relations: "logical laws are maximally general in that the only vocabulary required for their expression is the topic-universal vocabulary required for statements on any topic whatsoever" (Ricketts 1996, 123). ${ }^{4}$ We can call this the Required Vocabulary Interpretation of generality.

It seems clear that no special feature of the vocabulary used to express the logical laws can really distinguish the logical laws from those of the other sciences, since obviously non-logical truths can be stated using only that same vocabulary: for example, the truth that there exist five non-logical objects. ${ }^{5}$ Ricketts recognizes this, and his conclusion is that talk of "generality" is not intended to provide any real demarcation of logical laws. ${ }^{6}$ Ultimately, then, Ricketts thinks that "Frege has only a retail conception of logic, not a wholesale one. He tells us what logic is by identifying specific laws and inferences as logical...[he] does not state a defining criterion of the logical” (Ricketts 1996, 124). In particular, "generality" is not such a criterion.

\footnotetext{
${ }^{4}$ In earlier work, Ricketts seems to have missed the fact that logic has its own concepts and objects, claiming that "the laws of logic do not mention this or that thing." (Ricketts 1985, 4.) Sometimes he seems to express a slightly weaker characterization of these concepts: they "appear in thought and discourse on every subject matter whatever." (Ricketts 1997, 138.)

${ }^{5}$ i.e., objects that are not value-ranges, truth-values, etc. This kind of example appears in Heck 2012, 35-36.

${ }^{6}$ Like the rest of the notions that Frege uses to describe what logic is, Ricketts thinks this one is "irremediably fuzzy." (Ricketts 1997, 151.)
} 
The claim that Frege did not successfully distinguish the laws of logic from the others is very widely accepted, and by a range of commentators who disagree about central aspects of Frege interpretation, including Warren Goldfarb, ${ }^{7}$ Patricia Blanchette, ${ }^{8}$ Jamie Tappenden, ${ }^{9}$ and Richard Kimberly Heck..$^{10}$ Some of these authors think Frege was actively seeking a distinguishing feature that he had not yet found, while others think he had principled reasons for thinking a genuine demarcation impossible, ${ }^{11}$ but they agree that what he says about "generality" is not sufficient, and that he knew it.

This agreement is premature. Frege never acknowledges that some non-logical truths have the same generality as logical laws, and before invoking the generality that gives the laws of logic a special claim to the name "laws of thought," he emphasizes that "how the logical laws are conceived" will be "decisive for the treatment of this science," and that we must have the right conception of them if we are to prevent "the ruinous incursion of psychology into logic" (Frege 1893, xiv). This gives the strong impression that he at least thought that he was providing us with a distinguishing feature of the logical laws, which will allow us to conceive of them in such a way that we can, for example, see that psychology will be wholly irrelevant to them. ${ }^{12}$ This means that we should look

\footnotetext{
${ }^{7}$ "Frege's conception of logic is retail, not wholesale. He simply presents various laws of logic and logical inference rules, and then demonstrates other logical laws on the basis of these. He frames no overarching characteristic that demarcates the logical laws from others." (Goldfarb 2001, 30.)

8 "He gives no general characterization of the principles or truths of logic. He simply exhibits a small handful of what he takes to be self-evidently logical truths and inference-rules..." (Blanchette 2012, 147.)

9"It is true that nowhere does Frege give a criterion of the logical, although this could simply reflect that he had not arrived at one." (Tappenden 1997, 213.)

${ }^{10}$ Frege "was struggling with...questions about the nature of logic...he was developing a conception of logic in which [semantic notions] would play a fundamental role," but never arrived at a settled view. (Heck 2012, 38.)

${ }^{11}$ Goldfarb, for example, thinks that Frege's principled commitment not to do "semantic" theorizing would rule out a substantive criterion of the logical. (See, e.g., Goldfarb 2001.) But such commitments would at most rule out particular kinds of demarcation for logic, like those involving a substantive use of a truth-predicate applied to sentences.

${ }^{12}$ Goldfarb tries to dissolve this tension by quoting Frege's claim that he has provided only a "rough indication of the goal of logic." (Goldfarb 2001,31.) This sounds to Goldfarb like an admission that what he has said about generality is not really a way of demarcating the logical laws. But the "roughness" claim appears only in the unpublished discussion of generality, while the more complete discussion in
} 
carefully for an understanding of "generality" according to which, given the rest of what Frege thinks, it at least plausibly distinguishes the logical laws from the others-unless, of course, the evidence for an interpretation that does not, like the Required Vocabulary Interpretation, is overwhelming.

For that interpretation, however, the evidence is thin. The mere fact that logic has its own vocabulary does not motivate interpreting the generality of its laws by reference to that vocabulary. The passages in which Frege claims that the logical laws are special because of their generality makes no mention at all of the vocabulary of logic, nor of the concepts and objects to which that vocabulary refers. I suggest that this interpretation results from blending what Frege himself says with someone else's ideas-it is Quine who endorses the "widely applicable method of demarcating a branch of science...the method of listing the vocabulary," so that for Quine, "The logical truths...are the truths in which only the logical...vocabulary occurs essentially" (Quine 1986, 399). ${ }^{13}$ Since there is no good textual reason to think Frege had this in mind with his talk of generality, we should not accept the Required Vocabulary Interpretation.

\section{Generality: The Normative Interpretation}

We have seen Frege claim that the task of logic is "that of saying what holds with the utmost generality for all thinking, whatever its subject matter.' But if logic's generality has to do with "all thinking," it must have to do with the laws in their prescriptive aspect,

Frege 1893 contains no such claim. Moreover, what Frege strictly says in the unpublished discussion is that he is trying to "roughly make the goal recognizable." ["ungefähr das Ziel kenntlich...machen."] Frege emphasizes that any "roughness," derives from "the author's inadequacy and the awkwardness of language" rather than from the absence of something sharp that distinguishes the logical laws from the others.

${ }^{13}$ We see this Quinean source when the claim is put in terms of "vocabulary" rather than in terms of the special concepts and objects that Frege himself claims logic has. The fact that the logical vocabulary can be used to state apparently non-logical truths is sometimes raised as a problem for Quine: e.g., footnote 35 of Parsons 1986. 
because it is only in that aspect that these laws are especially concerned with thinking at all. In the same way, the other central claim that mentions generality explains it in terms of a universal prescription for thinking: "they are the most general laws, prescribing how to think wherever there is thinking at all." This observation leads us to the Normative Interpretation of generality: as John MacFarlane puts it, "the kind of generality that distinguishes logic...is a generality in the applicability of the norms it provides" (MacFarlane 2002, 37). All thinking ought to be in conformity with these laws, and that is what is distinctive of them.

Frege's own discussions of generality clearly point us in this direction, and this interpretation has been gaining adherents recently. But there is something odd about the way it is usually endorsed. Commentators tend to state the Normative Interpretation, but then immediately make additions to the basic claim that these laws are special because they prescribe for all thinking. For example, they add that the logical laws are general in that it is constitutive of thinking that it ought to proceed in conformity with the laws of logic, ${ }^{14}$ which adds the metaphysical claim that what makes the activity of thinking what it is is that these laws prescribe for it. One author adds that Frege's notion of generality has "an even more profound dimension: to count as a thinker at all one must acknowledge the categorical normative authority that logic has" (Taschek 2008, 384). ${ }^{15}$ Neither addition is implied by Frege's basic claim that the laws of logic are special because they tell us "what holds with the utmost generality for all thinking, whatever its subject matter." Perhaps Frege accepts these additional claims, and perhaps not-but either way, why do commentators build them into his talk of generality?

\footnotetext{
${ }^{14}$ Some of MacFarlane's own statements express this additional constitutive element: "Logic is general in the sense that it provides constitutive norms for thought as such, regardless of its subject matter." (MacFarlane 2002, 37.) See also Taschek 2008, 383: "what is distinctive about logical laws...is...that in an important sense they issue in, while the laws of physics do not, constitutive norms of thinking as such."

${ }^{15}$ This idea is also tentatively endorsed in Steinberger 2017, 152.
} 
We will find an answer to this question in a moment. For now, let us stick with the basic Normative Interpretation of generality. It identifies a distinctive feature of logical laws only if we ought to think in conformity with the logical laws in all of our thinking, whereas for every non-logical law, there is some thinking that is permitted not to be in conformity with it. Whether or not that is so depends on what these prescriptions are: on what exactly Frege means by "thinking," and "conformity."

Though Frege sometimes identifies thinking with "the grasp of a thought," (e.g.: Frege 1918-1919a, 355) MacFarlane thinks we should “take Frege's talk of norms for thinking as talk of norms for judging." I agree, for three reasons. ${ }^{16}$

1. Frege tells us to read it this way. He offers (in passing) a correction to his tendency to talk about these laws as applying to "thinking" and "thought": "if we call them laws of thought, or, better, laws of judgement..." (Frege 1897a, 145; my italics). ${ }^{17}$ What he is saying would be better put using the word "judgement."

2. In the relevant sections, Frege identifies "the goal" of thinking as truth (See Frege 1897a, 128). But it is only judging-"the acknowledgement of the truth of a thought"that has truth as its goal (Frege 1918-1919a, 356). ${ }^{18}$ So "thinking" here must be judging.

3. In these sections, Frege freely switches between "think" and "judge". For example, while the claims about generality are in terms of "all thinking," he switches to talk of "prescriptions for making judgements," and "prescriptions to which our judgements must conform...if they are to remain in agreement with the truth" (Frege 1897a, 145). This lack of any marked distinction between "thinking" and "judging," suggests that they refer to the same thing.

By "thinking" in conformity with a law, then, Frege probably means "judging" in conformity with it. (This is not to say that Frege would deny that the laws of logic issue

\footnotetext{
${ }^{16}$ The reason MacFarlane gives in favour of his reading is close to one of mine, but his formulation depends on assumptions about "conformity" that we should keep separate.

${ }^{17}$ The original reads: "Wenn man sie also Denkgesetze oder besser Urteilsgesetze nennen will, so muss man nicht vergessen, dass es sich dabei um Gesetze handelt, die wie die Sittengesetze oder Staatsgesetze vorschreiben, wie gehandelt werden soll...”

${ }^{18}$ Truth is not the goal of grasping thoughts, because sometimes "knowledge of the truth is attained precisely through our grasping a false thought" as in a proof by reductio (Frege 1918-1919b, 375). See also Frege 1892, 34.
} 
prescriptions for other mental activities, too. The point is that, in the passages in which Frege distinguishes logical laws from the others by claiming that they prescribe for all "thinking," he is referring only to judging. Even if these laws prescribe for other activities, we can see what is special about them by focussing on judging alone.) I will call this interpretive suggestion "Thinking=fudging."

It is harder to know what Frege means by "conformity." Since Frege says that our thinking must be in "conformity" with the logical laws if it is "not to fail of the truth," conformity must be a relation such that, whenever our thinking fails to bear it to logical laws, we are not thinking something true. The obvious candidate for this relation is consistency, which looks to be what MacFarlane has in mind: his examples are prescriptions not to judge things that are, collectively, inconsistent with logical laws. ${ }^{19}$ On this interpretative suggestion, which I will call "Conformity=Consistency," to think in conformity with a law is to think only thoughts that are not collectively inconsistent with it.

On the Normative Interpretation, supplemented with both Thinking=fudging and Conformity=Consistency, Frege is saying that the laws of logic are those with which everything we judge ought to be collectively consistent. But there is a problem: this feature obviously cannot distinguish the laws of logic from those of other sciences, because all judging ought to be of what is collectively consistent with every law of every science. The following argument shows why this is.

S) Suppose that I am judging, and L is a law of some science.

P1) All judging ought not proceed in a way that fails to reach the goal of judging. (This is why Frege thinks that the prescriptions apply to our thinking at all. They answer our question "How must I think in order to reach the goal, truth?" (Frege 1897a, 128).

C1) Therefore, I ought not judge in a way that fails to reach the goal of judging. (S and P1)

\footnotetext{
${ }^{19}$ i.e.: "One ought not believe both a proposition and its negation." (MacFarlane 2002, 36.) A perhaps more general statement of what the prescriptions are comes later: "a thinker ought not make judgements that are incompatible with [the laws]."
} 
P2) To judge things that are collectively inconsistent with $\mathrm{L}$ is to fail to judge only true things. (This is because laws are truths, and what is inconsistent with a truth is not true.)

P3) The goal of all judging is to judge only true things. (The quotes above identify "truth" and "not to fail of the truth" as the goal.)

C2) Therefore, to judge things that are collectively inconsistent with $\mathrm{L}$ is to judge in a way that fails to reach the goal of judging. (P2 and P3)

C3) Therefore, I ought not to judge things that are collectively inconsistent with L. (C1 and C2)

It looks like the Normative Interpretation cannot demarcate the logical laws after all.

This, I suggest, is why commentators do not rest for long with the Normative Interpretation itself: they do not really believe that it identifies a distinctive feature of the logical laws at all. To find a distinctive feature, they think we must go beyond Frege's normative claim and make a metaphysical claim about what makes thinking thinking, or a claim about what all thinkers must acknowledge. This would give Frege the chance to say: even though all laws prescribe for all thinking, only in the case of the logical laws is it constitutive of all thinking that they prescribe for it-so they are special. Or the chance to say: even though all laws prescribe for all thinking, only in the case of the logical laws is it impossible to be a thinker while failing to acknowledge their authority-so they are special. This is to abandon Frege's claim that the logical laws are special because they say "what holds with the utmost generality for all thinking, whatever its subject matter," and "prescribe universally the way in which one ought to think if one is to think at all." It is to admit that this normative feature of logical laws is not special after all.

I think this line of thought is a mistake. Frege says that the logical laws are distinctive because they prescribe for all thinking: our clear interpretive task is to make sense of how he can believe that. ${ }^{20}$ The key is to see that "conformity," is not just consistency.

\footnotetext{
${ }^{20}$ Whether or not Frege accepts those other claims, then, is a side-issue, which I will not try to settle here-but I will say what I think. Frege does not accept that it is impossible to be a thinker without acknowledging the normative authority of the logical laws. It is central to his discussion of the so-called "logical alien" that though we may be unable to bring ourselves to reject (or even doubt) the normative
} 


\section{Systematic Conformity}

So far, we have seen that according to Frege, it is distinctive of logical laws that all thinking ought to be in conformity with them, and by "thinking," he probably means judging. But if this is to be a distinguishing feature of these laws, conformity must be some relation such that if any judging fails to bear that relation to the logical laws, that judging will "fail of the truth", whereas for each law of the other sciences, there is some judging that need not bear that relation to that law in order to "remain in agreement with the truth." The argument above shows that the consistency of what is judged with the law is not such a relation. In fact, it is difficult even to think of such a relation. (Give it a try!) But if we recall some features of the way Frege thinks about truth, this relation comes into view.

In several places, Frege explains that when he talks about "truth," he means only what we might call "scientific truth." 21 He says that "in logic, we are concerned with truth in the strictest sense of the word," (Frege 1895, 226) which he calls "truth in the scientific sense" (Frege 1906a, 186; Frege 1914, 232) and "that sort of truth which it is the aim of science to discern." (Frege 1918-1919a, 352). Though it is not immediately clear what the point of these clarifications are, they ultimately prove to express a substantive restriction or assumption: one that allows Frege to argue that certain words cannot be used to express truths on the grounds that they "are illegitimate in science," (Frege

authority of a law of logic, this "hinders us not at all in supposing beings who do reject it." (Frege 1983, Introduction.) To "reject" a law or its normative authority requires thinking, so such beings would be thinkers who reject the authority of the logical laws. (The only way to escape this point is to endorse the heroic attempt in Conant 1991 to read Frege as ultimately forced to retract many of the claims he makes in his discussion of the logical alien, as "a ladder which one climbs up and then throws away.") On the other hand, I think that Frege does accept that it is constitutive of thinking that it ought to be consistent with the laws of logic, but that this is not distinctive of them; it is also constitutive of thinking that it ought to be consistent with the laws of physics. What is constitutive of thinking is just to have truth as its goal, and both sets of laws are true.

${ }^{21}$ For an illuminating discussion of some aspects of scientific truth in Frege, see Weiner 1996. 
$1895,228)^{22}$ or are unsuitable "for conducting proofs" (Frege 1896, 115). ${ }^{23}$ Frege seems to assume that only what is suitable to figure in science-proof-based science-can be true.

These are not the only places in which Frege makes this assumption. Consider his well-known claim that to locate a truth in the analytic/synthetic, a priori/empirical dichotomy, we must "find the proof and follow it back to the primitive truths" (Frege 1884, $\S 3)$. He is assuming that, with the exception of primitive truths, every truth has a proof. He makes that same assumption when he supposes that certain truths about numbers might be "unprovable" and immediately concludes that in that case they would all be "primitive truths" (Frege 1884, §5). This would be trivial if there were no more to being a "primitive truth" than being a truth with no proof. But Frege introduces the notion of a primitive truth in connection with his official account of proof: to be a primitive truth is to be an ultimate premise in scientific proofs. ${ }^{24}$ He depends on this fact in arguments. For example, he denies that there can be infinitely many primitive truths, on the grounds that there is a "need of reason" that the "foundations" of a science-the ultimate premises of its proofs-be "surveyable" (Frege 1884, §5). To assume that all truths are provable or primitive, then, is to assume that all truths have a place in a scientific system of proof,

\footnotetext{
${ }^{22}$ In the relevant passage, these are Frege's grounds for denying that fictional names can be used to express truths, in spite of the common-sense claims that lead to the philosophical discussion of truth in fiction. He reminds us that we are "concerned with truth in the strictest sense of the word."

${ }^{23}$ In the relevant passage, Frege denies that sentences involving vague terms can be true, on the grounds that reasoning with such terms leads to sorites-style problems: "the fallacy known by the name of 'Acervus'." In response to the common-sense objection that "such words are used thousands of times in the language of life," apparently to say true things, Frege replies, "Yes; but our vernacular languages are also not made for conducting proofs."

${ }^{24}$ As de Jong 1996 (300) comments on the dichotomy of truths above: "Frege places and presents these distinctions from the outset within the framework of the aristotelian [i.e. proof-system-based] model of science. Without this model, what Frege says about these distinctions is nearly incomprehensible." Frege 1914, 204-205 introduces primitive truths as follows: "If we start from a theorem and trace the chains of inference backwards until we arrive at other theorems or at axioms, postulates, or definitions, we discover chains of inference...terminating with the theorem in question. The totality of these inferencechains constitutes the proof of the theorem...Science demands that...we do not rest until we come up against something unprovable...If we assume that we have succeeded in discovering these primitive truths, and that [the science] has been developed from them, then it will appear as a system of truths that are connected with each other by logical inference."
} 
whether as theorem or as ultimate premise.

Such systems are of the first importance for Frege: he announces, for example, that "science only comes to fruition in a system," so that "we shall never be able to do without systems" (Frege 1914, 242). ${ }^{25}$ The reason these systems are so important to Frege is that he thinks it is only by discovering them that we achieve our central cognitive goals: to grasp the nature or essence of the subject in question, ${ }^{26}$ to have command or mastery over its domain, and to understand and explain its phenomena. ${ }^{27}$ That is why he thinks that the ultimate aim of our scientific activity must be to have such systems, and it is why he spends so much effort policing the boundaries between sciences: ${ }^{28}$ if we wrongly include a certain truth in the system of a certain science, we cannot correctly grasp the "nature" of the subject. In holding the systematic view of the aim of science, Frege is in agreement with most thinkers of his day. ${ }^{29}$

Frege's exclusive concern with a "sort of truth" that figures in science so conceived is also shared with others belonging to the dominant philosophical trend at the time. Kant saw an essential connection between the understanding's goal of truth and reason's goal

\footnotetext{
${ }^{25}$ In general, see especially Frege 1884 (§3), Frege 1880-1881, and Frege 1914 for Frege’s commitment to the systematic conception of science.

${ }^{26}$ It is the primitive truths of the systems that give us this grasp: "The essence of mathematics has to be defined by this kernel of truths, and until we have learnt what these primitive truths are, we cannot be clear about the nature of mathematics." (Frege 1914, 204-205.)

${ }^{27}$ Our command over a domain is inversely proportional to the number of primitive truths in the system: a "greater command of the material" results when we assemble the "large mass of detail under a more comprehensive point of view," so that "The fewer the number of primitive sentences, the more perfect a mastery can we have." (Frege 1880-1881, 39.) Frege further identifies this mastery with possessing an explanation, because the "essence of explanation lies precisely in the fact that a wide, possibly unsurveyable, manifold is governed by one or a few sentences." (Frege 1880-1881, 36.) Incidentally, Friedman 1974 would introduce this idea into contemporary philosophy of science as the "unification theory of explanation," though he seems to be unaware that Frege is a predecessor: "the only writer that I am aware of who has suggested that this [unification]...is the essence of explanation...is William Kneale." (15)

${ }^{28}$ For examples of such policing, see Frege 1879-1891, 5 and Frege 1914, 203: logic does not include psychological truths, physics does not include chemical truths, physics does include geometrical truths, jurisprudence does include both historical and psychological truths, and so on.

${ }^{29}$ See de Jong and Betti 2010 for discussion of the prevalence of this view of science.
} 
of systematic science, ${ }^{30}$ and the major figures of the dominant Neo-Kantian movement of Frege's day made much of this point. Hermann Cohen, for example, takes Kant to have shown that the philosopher's concerns are "not about cognition as such...but rather, mathematical-scientific cognition," whose goal, accordingly, is mathematical-scientific truth (Cohen 1885, 56). ${ }^{31}$

When Frege says that the goal of judging is truth, then, he means that the goal is to judge something that has a place in some scientific system of proof. On this view, the status of a truth as such depends on the relationship that it bears to the other laws in a scientific system. Suppose, for example, that I judge that all whales are mammals: a truth that has a place in the proof-system of zoology, but not that of geology, or (let us suppose) any other science. This law's status as a truth, then, depends on its place in the scientific system of zoology: on the relationship it bears in the proof-structure of that system to the other laws of that science. By contrast, it has no important relationship to, say, the geological law of superposition.

This points us to a relation with the features that we need to make sense of Frege's talk of "conformity": a relation which our judging sometimes must bear to laws in order to be true, which is stronger than mere consistency. I suggest that to judge in conformity with a particular law is to judge something that only has a place in a scientific system that

\footnotetext{
${ }^{30}$ As Abela 2006 puts it, the fact that "lacking the top-down component of rational [i.e. systematic] unity, the understanding has no employment...puts the demands of systematicity near the center of Kant's account of cognition." (421) This reading is motivated by Kant's claims that "the law of reason to seek [systematic] unity is necessary, since without it we would have...no coherent use of the understanding," and that reason "prepares the field for the understanding." (Kant 1781/1787, A651/B679. and A657-8/B6856)

${ }^{31}$ Cohen influentially interprets Kant's terminology to fit with this exclusive focus: he claims that Kant "discovered a new concept of experience," (Cohen 1871,3) on which "experience...must count as the total expression of all the facts and methods of scientific cognition." (Cohen 1885, 59.) Frege was certainly aware of Cohen's perspective; not only was it inescapable in the intellectual world at the time, but Frege $1885 \mathrm{~b}$ is a review of Cohen 1883, which is "Perhaps Cohen's most sustained and systematic attempt to present Kantian philosophy in historical connection to mathematical natural science." (Richardson 2006, 218.)
} 
includes that law. On this reading, when I judge the law that whales are mammals, I am judging in conformity with the rest of the laws in the science of zoology-the other laws on which this law's status as a truth depends-but not in conformity with the geological law of superposition. I will call this interpretive suggestion Conformity=Systematicity.

Let us see what the generality of the logical laws looks like, if we read "conformity" this way.

\section{The Systematic Generality of the Logical Laws}

Frege says that the laws of logic are special because of their generality. If we understand this in terms of the Normative Interpretation of generality, supplemented by Thinking= Fudging and Conformity=Systematicity, what this amounts to is: all our judging ought to be of what only has a place in a scientific system that includes the laws of logic. I will call the feature that this claim attributes to the laws of logic "systematic generality." Given that the goal of judgement is (scientific) truth and that all truths appear in scientific systems, another way to put what is special about laws that exhibit systematic generality is simply that they appear in every scientific system.

In evaluating other interpretations of Frege's notion of generality above, I employed two criteria of adequacy.

1. The problem with the Required Vocabulary Interpretation was that we must identify generality with a feature that, at least plausibly, distinguishes the laws Frege picks out as logical from the laws of the other sciences, given the rest of what he thinks: there cannot be obvious counterexamples. (We need not offer an interpretation on which Frege is correct about what is distinctive of logical laws, or even correct that all and only the laws he himself picks out as logical have the feature that he claims is distinctive of logical laws. Frege could have made a mistake about either point. But it cannot be obvious that not all the laws he sees as logical have the feature he identifies as distinctive of logical laws, or that some laws he sees as non-logical do have that feature.) 
2. I argued against those who make textually unwarranted additions to the basic Normative Interpretation that we must identify generality with a particular normative feature: what is special about logical laws must be that they (and only they) prescribe for all thinking in the relevant way.

An interpretation that can satisfy both of these criteria will be the best one we have. I will now argue that the interpretation in terms of systematic generality does satisfy them, and respond to an important objection to which each discussion gives rise. ${ }^{32}$

\section{First Criterion: Do the Right Laws Exhibit Systematic Generality?}

Given the rest of what Frege thinks, is it plausible that the laws he identifies as logical will appear in every scientific system, and that they are the only laws that will?

Scientific systems are systems of proofs, and Frege thinks all proofs employ logical laws. To prove a truth belonging to some particular science, he thinks we first prove various logical theorems from the axioms of logic, then instantiate those theorems for the relevant concepts and objects of the science in question, and finally use one of a few modes of inference together with the instantiated theorems and the nonlogical primitive truths belonging to the science to reach the desired conclusion. ${ }^{33}$ It is because every system includes such proofs that every system includes at least some logical laws.

But must they include all logical laws? If the logical axioms are included, the rest of the laws will appear as theorems, so the question is whether all Frege's axioms-

\footnotetext{
${ }^{32}$ The claim that the laws of logic appear in every science is sometimes attributed to Frege. (Burge 1992, for example, notes that Frege thought that "all sciences contained logic" (301), and May 2018, that "Frege's conception of science is...of an axiomatic system.... where the deductive base, for any given science, [includes] the Basic Laws [of logic]..." (128)) But I know of no discussion that makes it clear that this is what he thinks is distinctive of logical laws, or explains why the view that the laws he counts as logical are the only ones that appear in every system is a reasonable one for him to hold, or establishes any connection with the normative role that he claims for logic.

${ }^{33}$ See 34-35 of Goldfarb 2001 for this point and an example. There would be a potentially problematic circularity in appealing to systematic generality to characterize logical laws if it were built into the nature of these systems that the proofs within them have to be logical, but it is not-though Frege ultimately argues that it is a bad idea, it is consistent with the systematic conception of science to allow non-logical proofs, such as that from " $\mathrm{x}$ is a whale" directly to " $\mathrm{x}$ is a mammal."
} 
the full proof-resources of Frege's logical system-are needed in every system in order to prove all the truths that properly belong to the relevant science. Whether or not this is so depends on how wide a range of truths any proper science must include, and what it takes to prove them. If any arbitrary set of truths, no matter how small and homogeneous, could constitute a science, then some of the laws that Frege counts as logical would obviously not appear in all systems. But we have seen that the boundaries between sciences are not arbitrary: a genuine science has a nature or essence that we grasp when we have found a system including all and only the right truths. Furthermore, Frege's conception of the cognitive goals that we achieve by having systems implies that every system must include a very wide range of truths: for example, explanation is possible only when a system includes a "wide, possibly unsurveyable, manifold" of theorems (Frege 1880-1881, 36). ${ }^{34}$

One might have a specific worry here about Basic Law V. What need has the science of biology for an axiom about value-ranges? But since Frege thinks Basic Law V is the axiom needed for arithmetic, it follows from Frege's so-called "Pythagoreanism"-the view that arithmetic is needed in every science-that this law will be needed. ${ }^{35}$ One might think it implausible to maintain Pythagoreanism about as broad a range of sciences as Frege countenances: does even the science of jurisprudence require the resources of scientific arithmetic? But the view that it does was standard at the time, expressed in the most widely-read logic books. Hermann Lotze, for example, claims that all sciences require laws that exhibit the kind of order that can only be expressed using the resources of a scientific arithmetic. ${ }^{36}$ As E.E. Thomas explains regarding jurisprudence

\footnotetext{
${ }^{34}$ See the discussion of cognitive goals in section 4 above.

${ }^{35}$ See, for example, Beaney 1996 (66): "Pythagoreanism...had an epistemological dimension-that we can have no [scientific] knowledge of anything without ascribing it a number; and this fundamental Pythagorean belief was certainly endorsed by Frege..."

${ }^{36}$ See $§ 265$ of Lotze 1874, which was "perhaps the most widely read logic text in Germany during Frege’s early career." (Heis 2013, 122.)
} 
in particular, "Speaking of law in the judicial sphere, [Lotze] says that the aim of law is to establish a graduation in penalties that shall correspond to a graduation in offences, this graduation proceeding on a quantitative or mathematical basis" (Thomas 1921, 6).

What about the other direction? Will any of the laws Frege identifies as non-logical exhibit systematic generality? Since Frege thinks that some sciences, including geometry, are wholly a priori, no truths that can be learned only by experience will appear in all sciences. The laws of geometry, on the other hand, must appear in many other systems-but not every one. Frege holds, for example, that alongside the spatial "source of knowledge" on which the science of space depends, there is a temporal source of knowledge which gives rise to a science of time (Frege 1924/5a, 274), and these sciences are independent: just as truths about time do not appear in the science of space (Frege $1880,101)$, so claims about space will not appear in the science of time. Moreover, since Frege is Kantian enough to suppose that the pure intuition of space is the source of geometrical knowledge (see, e.g., Frege 1874 56-7, Frege $1884 \S 13$ and §89, and Frege 1903b, 273), he presumably thinks that there could be creatures with different forms of outer sense, who would investigate only sciences which contain no truths about space.

One might have a specific worry about a truth we considered in connection with the Required Vocabulary Interpretation: "There are at least five non-logical objects." If every science involves claims about particular non-logical objects, then this clearly non-logical truth would exhibit systematic generality. ${ }^{37}$ But Frege never claims that they do. On the contrary, he goes out of his way to argue for a point also emphasized by Lotze: that since laws concern concepts, they remain true even if nothing falls under the concepts (see, e.g., Frege 1884, $§ 47$ and Lotze 1874, Book III, Chapter II). ${ }^{38}$

\footnotetext{
${ }^{37}$ May 2018 attributes to Frege the claim that every science has a "subject-matter" of its own-a "domain of entities", which he seems to assume to be objects given to us by the relevant "source of knowledge." $(118,128$, footnote 8 .) I cannot see any clear evidence for this attribution.

${ }^{38}$ Based on what $\S 3$ of Frege 1884 says about the proof of empirical claims, Frege probably does think
} 
My interpretation, then, meets our first criterion of adequacy: it is plausible, given the rest of what Frege thinks, that the laws he identifies as logical are distinguished from the laws of other sciences by their systematic generality.

\section{Objection: This Precludes Understanding Frege's Logicism}

The view of logic that I attribute to Frege might seem to preclude understanding his logicist project: his attempt to show that arithmetic is a branch of logic. ${ }^{39}$ This worry can be expressed as the following three-part objection.

Let us suppose that Frege understood logic in the way I suggest. In that case:

1. It would be easy to show that arithmetical truths are logical: we need only observe that every proper science must include the truths of arithmetic. But Frege himself clearly thinks it is important to actually prove these truths from logical axioms.

2. Even if for some reason Frege wanted to actually prove the truths of arithmetic from logical axioms, there would be no need for him to get mixed up with the notorious Basic Law V. Frege could have simply identified Hume's Principle or some standard set of arithmetical axioms as axioms of logic, since their logicality would not be in doubt. Even if he were for some reason attached to Basic Law $\mathrm{V}$, surely after he came to see that it was unacceptable, he would have calmly swapped it out for one of these other candidates. But Frege himself does not do so, instead responding with despair.

3. Even if for some reason Frege could not complete his logicist project without Basic Law V, he would be unable ever to abandon logicism and seek a different foundation for arithmetic, since he would still recognize that every proper science must include the truths of arithmetic. His view of logic itself would imply that he is stuck with logicism. But near the end of his life, Frege himself abandons logicism: he claims that arithmetical truths have a geometrical source, while continuing to deny that geometrical truths are logical (e.g., Frege 1924/1925b).

It is easiest to see why the objection fails in its second part: it assumes that the only

that all empirical sciences involve claims about particular objects, but I know of nothing he says that has this consequence for a priori sciences. (Even if he were to hold that all such sciences depend on pure intuition, $\S 13$ of Frege 1884 claims that apparently particular objects yielded by pure intuition "are not particular at all.")

${ }^{39}$ Thanks especially to Joan Weiner for raising this objection. 
constraint on axioms of logic is that they be logical laws. That is why it seems that, before or after Russell's Paradox, Frege could have based arithmetic on Hume's Principle or a standard set of axioms for arithmetic, rather than Basic Law V. But it was never uncertainty about whether these other truths are logical that disqualified them from being axioms. ${ }^{40}$ There are other constraints: for example, in addition to being logical, axioms must be "self-evident" and "unprovable" (e.g., Frege 1884, §5). It is a major question just what these additional constraints amount to, but since Frege accepts such constraints, my account does not imply that he could have based arithmetic on one of these candidates rather than Basic Law V. ${ }^{41}$

These constraints make it difficult to actually provide logical foundations for arithmetic, which is one reason to do it-which brings us to the first part of the objection. Any reading of Frege must acknowledge that he takes himself to have powerful reasons to accept logicism about arithmetic even before he completes the project. ${ }^{42}$ But no matter how strong these arguments are, the difficulty of providing logical foundations remains a source of doubt: of concern that the arguments for logicism might contain some kind

\footnotetext{
${ }^{40}$ Frege never expresses doubts about the logicality of Hume's Principle or the Peano Axioms, and he proves them both from the axioms of logic in Frege 1893. (See Heck 1993 for details.) Whatever the problem with Hume's Principle that Frege sees at $\S \S 66-67$ of Frege 1884, nothing he says suggests that it is a problem for its logicality.

${ }^{41}$ As Shapiro 2009 argues, any epistemological view on which we can come to know that something is true in the way appropriate to axioms by seeing that it plays some kind of systematic role must be one on which "self-evidence is simply not part of the picture." Frege's insistence on self-evidence, then, ensures that recognizing that a truth has the systematic role appropriate to a logical law provides no guarantee that the truth can be known in the way axioms must be. Indeed, on plausible interpretations of what self-evidence amounts to such as that of Jeshion 2001, it proves difficult to find axioms that meet the constraint, since "the simplest propositions of arithmetic [including standard sets of axioms] are not self-evident.” (963)

${ }^{42}$ Frege offers arguments for logicism-or for the related claim that the foundations of arithmetic can be neither intuitive nor sensory-at Frege 1874 56-57, Frege 1882 100, various places in Frege 1884, and Frege 1885a 112-113. Though it is a major question how those arguments are to be understood, he clearly thinks they establish logicism as the only option: that is why his initial response to Russell's Paradox is to claim not only that he no longer sees how to provide a logical foundation for arithmetic, but that without such a foundation, he no longer sees how "arithmetic can be founded scientifically" at all. (See Appendix 2 of Frege 1893.)
} 
of mistake. Until we find the foundations, these reasons for doubt render logicism, in that sense, merely probable. ${ }^{43}$

This brings us to the third part of the objection. Any reading of Frege's views on logicism must acknowledge that once he comes to think the difficulties of finding suitable logical axioms are insurmountable, and to claim that arithmetic is a branch of geometry rather than logic, he has come to think that his former arguments for logicism must have contained a mistake after all; most obviously, he must see a flaw in his arguments that arithmetic could not have its source in intuition. He does not say what is wrong with those earlier arguments, and it is a major question just what he has come to reject. But there is only a problem for my reading if he continues to think that arithmetical laws appear in every science. But whatever else he has come to reject, he surely has come to reject that claim. If space is the form of our sensibility, and the pure intuition of space is the source of our knowledge of geometry, then a consequence of accepting a geometrical source for arithmetic is that arithmetical truths will not appear in all scientific systems: the sciences pursued by beings with different forms of sensibility than ours, for example, will include neither geometry nor arithmetic. This enables him to hold that arithmetic has geometrical grounds while maintaining the account of logic in terms of systematic generality.

This objection, then, connects with major questions about Frege's logicism whose answers are beyond the scope of this paper-but none of them become especially difficult to answer once we accept that Frege understood logic the way I suggest. Rather, if mine is indeed the best reading of Frege's mature views about logic, we should expect the connections that we are led to see between Frege's philosophy of science and his

\footnotetext{
${ }^{43}$ Frege himself claims that making it probable is what his arguments accomplish at Frege 1884, §87. The difficulty of finding foundations may not be the only such reason for doubt. Weiner 2010 (35) finds another in the fact that unlike paradigmatic logical truths, arithmetical truths deal with particular objects.
} 
philosophy of logic to help us make new progress on those questions.

\section{Second Criterion: Is This a Normative Interpretation?}

I noted above that we can put what is special about a law that exhibits systematic generality this way: it appears in every scientific system. But this claim does not include any "oughts," and the second criterion of adequacy was that what is special about the logical laws must be a normative feature: they and only they prescribe for all judging in the way he describes. Does this account satisfy that criterion?

It does. The criterion is that the laws of logic must be the only ones that tell us, in that way, how all our judging ought to be. On my reading, they are: all our judging ought to be of what only has a place in scientific systems that include the laws of logic, and that is not true of any other laws. It is not part of the criterion of adequacy that this be the only thing that is special about them.

One might wonder if there is any reason Frege appeals to the explicitly prescriptive characterization if equally good descriptive characterizations are available. I think that there is. In a sense, the prescriptive characterization makes more explicit something that is contained in the only apparently "descriptive" characterization in terms of systems. Frege claims that the word "true" belongs with the words "beautiful" and "good" (e.g., Frege 1918-1919a, 351). He also calls the True and the False truth-values, and not just because they are the values of certain functions for certain arguments. ${ }^{44}$ (For one thing, they are equally the arguments of certain functions that yield certain values, and he does not call them "truth-arguments."; for another, everything is the value of certain functions for certain arguments, and he does not call everything a "-value.") Such value-terms, plausibly, are normative in the sense that to understand them is to know

\footnotetext{
${ }^{44}$ This functional reading is suggested by Glock 2015.
} 
something like the standard formula of Frege's day: that one ought to think the True, feel the Beautiful, and will the Good. ${ }^{45}$ If Frege sees talk of truth itself as normative, then given the connection between scientific systems and truth described in section IV, it will be the same for systems: one cannot understand talk of scientific systems without understanding that all judging ought to be of what has a place in such a system.

\section{Objection: A Deeper Account Must Be Available}

Someone might admit that Frege thinks that all judging ought to be of what only has a place in a scientific system including the logical laws, and that this normative feature is what he has in mind when he calls them "general," but insist that this cannot be the whole story: that he could not be satisfied with this account, because there must be an explanation of why these laws appear in every science. This explanation, moreover, must proceed in terms of some more fundamental feature that those laws share-perhaps a semantic or metaphysical feature-and once this feature is found, it will provide a deeper characterization of what it is to be a logical law. If so, the normative claim must be a kind of place-holder, until that deeper characterization can be found. ${ }^{46}$

To see the flaw in this illuminating objection, consider an analogy. Suppose the same group of philosophers-call them "the Sages"-attended all of the recent great philosophy conferences, including ones devoted to sub-fields in which the Sages do not specialize. The Sages thus share a normative feature: they attended every recent great philosophy conference-that is, every one at which a large and intellectually diverse group of people talk together in ways that lead to the kind of work that philosophers ought to produce. It is perfectly reasonable to ask for an explanation of why these philosophers

\footnotetext{
${ }^{45}$ E.g., Windelband 1883, 328: "thinking has the goal of being True, willing the goal of being Good, and feeling the goal of grasping the Beautiful."

${ }^{46}$ Thanks especially to Richard Heck and John Campbell for raising this worry.
} 
appeared at every great conference. We may learn that these people do not just show up at conferences that would anyway be great-rather, each one of them helps to make philosophy conferences great. Though each Sage does interesting work on some philosophical topic, their primary contribution to great conferences is to facilitate the kind conversations between other philosophers which lead to the kind of philosophy that philosophers ought to produce. Such details-all normative ones, to be understood in terms of the work philosophers ought to produce-explain why the Sages are at every great conference. At the analogous point, I claim, Frege's account of logical laws stops: to be a logical law is to appear in every proper scientific system. These laws appear in every such system because they serve to connect other truths by proof in ways that yield such systems: ways that enable the systems to satisfy our cognitive goals. Those who object that this account of logic would not be deep enough might, then, also object that there must still be some deeper explanation of being a Sage: some further feature that the Sages share which explains why they share the normative feature.

But there might really be no such thing. One Sage might have a sharp eye for implication relations, enabling her to point out when two philosophers' projects intertwine in hard-to-spot ways; another might have an exuberant enthusiasm which indirectly helps other philosophers see what is interesting in each other's work; a third Sage's skeptical disposition might lead complacent philosophers to see that their work could be strengthened and seek contact with others for that purpose, and so on. Though each Sage has some psychological feature that explains how he or she does what he or she does, there may be no such feature they all have in common which explains why they have the normative features they share. In that case, there would be no deeper explanation of what it is to be a Sage. I expect that though Frege would agree that each law has some non-normative features that explains how it serves to connect the particular truths that 
it does, he would deny that there is a single non-normative feature that all and only the logical laws share which can explain their having the normative feature they share.

One might try to insist that philosophically or scientifically legitimate features and categories must always be explained or grounded in terms of non-normative ones. But whether or not such an assumption could be justified, there is not the slightest reason to attribute it to Frege. Such assumptions were certainly far from common ground in Frege's intellectual context: in fact, the most widely read logician of the day claims rather to be "certain of being on the right track, when I seek in that which should be the ground of that which is" (Lotze 1879, Volume III, Conclusion).

\section{Should We Endorse Frege's View?}

The main task of this paper, to understand the generality that Frege thinks distinguishes the laws of logic from those of other sciences, is complete. But the views of the normativity and the nature of logic that I have ascribed to him are largely absent from contemporary discussions of these topics. ${ }^{47}$ Accordingly, readers might be disappointed to learn that Frege holds them: despite being the founder of modern logic, Frege's views about the philosophy of logic might seem unavailable to logicians today as a consequence of being bound up with outdated views about truth and science.

Before I conclude, then, I will make a preliminary case that Frege's views should still be taken seriously today. I will not do so by defending his views of truth and science, but by showing that we can abstract from the details of those views to arrive at defensible core conceptions of the normativity and the nature of logic. I will begin with the normative role that Frege claims logical laws play, and then discuss the idea that playing

\footnotetext{
${ }^{47}$ See, for example, the absence of anything like Frege's view from the survey of positions in Steinberger 2016.
} 
this normative role is the distinctive feature of logical laws.

\section{On the Normativity of Logic}

Frege's interest in scientific truths and scientific systems derives from his conviction that it is only by having such systems that we understand the world and explain its phenomena: major cognitive goals whose status as such yields prescriptions for our cognitive activity. His core idea about the normativity of logic is that logical laws play an essential role whenever we achieve such goals. Leaving aside Frege's particular conception of those goals, then, we can identify a broadly Fregean view of the normativity of logic as one on which the logical laws play an essential role whenever we meet major cognitive goals which provide prescriptions for our cognitive activity.

So understood, leading contemporary accounts of major cognitive goals at least make possible, and sometimes imply, a broadly Fregean view of the normativity of logic. To take one example: a leading general theory of explanation is the "unificationist" theory defended by Philip Kitcher, according to which an explanation is an argument that is an instance of one of the few "argument patterns" that best "systematize" the "set of statements endorsed by the scientific community." Kitcher further endorses the "deductive chauvinist" view that the only explanatory argument-patterns are deductively valid (Kitcher 1989; see also Friedman 1974). This yields an essential role for logical laws in all explanations-reaching this cognitive goal in every case depends on the logical laws. Assuming that this cognitive goal yields prescriptions for our cognitive activity, Kitcher is committed to a broadly Fregean view of the normativity of logic. ${ }^{48}$

\footnotetext{
${ }^{48}$ To take another example: though there is much disagreement in the expanding literature on understanding, "if there is a common idea here it seems to be that understanding is directed at a complex...with parts or elements that depend upon, and relate to, one another." (Grimm 2012, 105. See, for example, Zagzebski 2001, Kvanvig 2003, Elgin 2006, and Pritchard 2009.) These dependencies and relationships paradigmatically include logical relations-for example, according to Kvanvig 2003, "understanding requires...an internal grasping or appreciation of how the various elements in a body of information are
} 


\section{On The Nature of Logic}

A broadly Fregean view of the normativity of logic makes space for a broadly Fregean view of the nature of logic, on which what is distinctive of logical laws is their having the normative role just described. Whether or not that is a good account depends on why it matters which laws count as logical in the first place. I focus here on two reasons, which we can call "looking after the future" and "looking after the past." 49

Consider a 20th-century analytic philosopher who announces that what is distinctive of philosophical truths is that they are true in virtue of the meanings of the words involved, so that the proper method for philosophy is linguistic analysis. This pronouncement might be revolutionary in spirit: regardless of what those called "philosophers" have hitherto been doing, its point is to orient our future investigations toward important truths that can be productively investigated. An account of the nature of logical laws that looks after the future would, in this way, identify a group of laws that are important and can be productively investigated. Like this analytic philosopher, when we look after the future of logic, we must in principle be prepared for revolution: we may need to deny that the questions and methods of those hitherto called "logicians" have anything to do with what logic really is.

But as Hartry Field has recently emphasized, we also want an account of logic to tell us "what people who disagree in logic are disagreeing about" (Field 2015, 35). More generally, an account of logic that looks after the past lets us see similarities and dif-

related to each other in terms of explanatory, logical, probabilistic, and other kinds of relations." (192193.) If logical relations prove to be required in every case, this implies a broadly Fregean view of the normativity of logic.

${ }^{49}$ Neither of these desiderata involve satisfying "pre-theoretical intuitions" about logicality. This goal of philosophy is unavailable, because there do not seem to be any pre-theoretical intuitions about this. As MacFarlane puts it, "Students beginning an introductory logic class typically have inferential intuitions, but they can be brought to distinguish logically valid inferences from materially valid ones only by instruction. All of our intuitions about logicality bear the stamp of theory." MacFarlane 2000, section 1.4. 
ferences among what prominent thinkers have said about logic as (not merely verbal but) genuine agreements and disagreements about some topic, pursued in reasonable ways. For example: if Kant denies that arithmetical laws are logical, and Frege holds that they are logical, we want an account of what logic is to let us see this as a disagreement about something, in which Frege and Kant say things in support of their views that are (at least plausibly) genuine reasons that count in favour of those views. When we look after logic's past, we must in principle be prepared to study what is merely a historical curiosity: a faithful account of what people have been arguing about under the name "logic" may require us to recognize that they were not arguing about anything that matters very much.

Ideally, we would not have to choose: our account of the nature of logic would let us see prominent thinkers as having reasonable agreements and disagreements (looking after the past) about genuinely important issues that can be productively investigated (looking after the future). By this standard, the broadly Fregean account of the nature of logic looks promising. It looks after the future because, as discussed above, cognitive goals whose achievement always involves a certain a set of laws remain a major focus of productive work in philosophy. Showing that it looks after the past is a major historical task, but let me give a sketch of the kind of interesting disagreements that a broadly Fregean view of the nature of logic enables us to see between Frege and three other important figures: Aristotle, Kant, and Carnap.

- Frege and Aristotle: One difference between Frege's logic and the syllogistic logic of the Analytics is that the latter does not allow for proofs involving multiple generality: from the premise that there is somebody whom everyone loves, we cannot prove that everybody loves at least one person. On the broadly Fregean view, this is a failing of Aristotle's logic only if such proofs are needed whenever we reach the relevant cognitive goals. Frege would argue that there are scientifically relevant proofs involving multiple generality-including those involving the continuity of a function and the notion of following in a series-and that some 
such proofs are needed every time we achieve our cognitive goals, because scientific arithmetic requires such proofs and is required in every scientific system.

- Frege and Kant: On the broadly Fregean view, to deny that arithmetical laws are logical is to deny that they are always required to reach our central cognitive goals. It might seem that there is no disagreement between Frege and Kant here, since Kant, too, identifies "proper science" as the way to achieve those goals, and claims that "a doctrine of nature will contain only as much proper science as there is mathematics capable of application there" (Kant 1786, Introduction). The disagreement is found in Kant's saying "mathematics" rather than "arithmetic." Kant argues that proper science must include some mathematics, ${ }^{50}$ but denies that it always requires arithmetic, because all creatures who share our faculties of reason and the understanding share our cognitive goals, but not all such creatures share the form of sensibility upon which arithmetic depends. Frege would argue that arithmetic does not depend on the form of our sensibility. ${ }^{51}$

- Frege and Carnap: Carnap is famous for his "principle of tolerance," according to which we are free to choose one or another logical system as a matter of "convention," based on the way we respond to "pragmatic" considerations like "efficiency, fruitfulness, and simplicity"; our choice is not constrained by "the striving after 'correctness"” (Carnap 1950, Foreword and section 2). On the broadly Fregean view, this is logical nihilism, as Carnap probably recognizes: while Frege had identified logic as the "ethics of thought," Carnap announces that "in logic, there are no morals" (Carnap 1937, §17). The substantive issue is whether or not there is a single set of laws that is in every case needed to reach the relevant cognitive goals. Frege would argue that many considerations Carnap calls "pragmatic" are actually aspects of the goals themselves. For example, Frege sees some of them as part of a kind of simplicity which it is "a basic principle of science" to achieve, and whose achievement is part of "the ideal of a strictly scientific method." (See Frege 1914, 242; Frege 1880-1881, 36; and Frege 1893, Introduction). ${ }^{52}$ (Later, Quine would ar-

\footnotetext{
${ }^{50}$ Kant's argument is that any science needs to have an a priori part "lying at the basis of the empirical part," but to cognize determinate natural things a priori requires "that [an] intuition...be given a priori," and any knowledge based in this way on "the presentation of the object in a priori intuition, is called mathematics."

${ }^{51}$ Of the many things Kant calls "logic", the broadly Fregean view implies that we should compare Frege's logic not only with "pure general" logic (which has no content at all) but with aspects of "transcendental" logic, which presupposes that the conditions on having the content appropriate for science are met in one way or another without assuming that they have been met by sensibility: what we study "distinguishes itself not merely from all that is empirical but completely also from all sensibility." (Kant 1781/1787, A65/B90.) MacFarlane 2002 argues that disputes between Frege and Kant must be about what Kant calls "pure general logic," since he thinks only this has the general normative role, but I think that transcendental logic is not a special logic, and that the difference between transcendental logic and pure general logic is one of aspect, not normative generality. (See Tolley 2012.)

${ }^{52}$ The central aspect of simplicity has to do with the number of primitive truths: As Frege 1914 puts it,
} 
gue in a similar vein that Carnap's apparently "pragmatic" considerations are actually part of the scientific goal itself: "What seemed to smack of convention....was 'deliberate choice, set forth unaccompanied by any attempt at justification other than in terms of elegance and convenience'... [but] surely the justification of any theoretical hypothesis can...consist in no more than the elegance or convenience which the hypothesis brings" (Quine 1960, section VI).

\section{Conclusion}

I hope to have made a start toward showing the promise of a broadly Fregean view of the normativity and nature of logic. But more centrally, I hope to have shown that Frege, at least, understands the nature of logic in connection with the ambitious cognitive goals that we achieve through discovering scientific systems: they are the laws that we depend on whenever we achieve those goals. The key to understanding Frege's claims is to recall that that the only "sort of truth" that he ever writes about is to be understood in terms of those same goals. This enables us to understand Frege's claim that it is distinctive of the laws of logic that they prescribe for all thinking. ${ }^{53}$

\section{Works Cited}

Abela, Paul. 2006. "The Demands of Systematicity: Rational Judgment and the Structure of Nature." In A Companion to Kant, ed. Bird. Oxford: Blackwell.

Beaney, Michael. 1996. Frege: Making Sense. London: Duckworth.

Beiser, Frederick. 2014. The Genesis of Neo-Kantianism, 1796-1880. Oxford: Oxford University Press.

Blanchette, Patricia. 2012. Frege's Conception of Logic. Oxford: Oxford University Press.

\footnotetext{
"Science...must...make the circle of...primitive truths as small as possible." (See also Frege 1879 (§13) and Frege 1884 (§2).) Frege does accept (e.g., in Frege 1914) that there can be some freedom in which logical laws are taken as axioms and which are proved as theorems, but not which truths are logical laws.

${ }^{53}$ For helpful discussions and comments on earlier drafts, I am thankful to audiences at IU Bloomington and the TiLPS History of Analytic Philosophy workshop, and to John Campbell, Eugene Chislenko, Gary Ebbs, Richard Heck, Richard Lawrence, John MacFarlane, Antonia Peacocke, Kirsten Pickering, Thomas Ricketts, Umrao Sethi, Hans Sluga, Justin Vlasits, Joan Weiner, and Yuan Wu.
} 
--- 1992. "Frege on Knowing the Third Realm." In Truth, Thought, and Reason: Essays on Frege, 299-316. Oxford: Oxford University Press. 2005.

Burge, Tyler. 1998. "Frege on Knowing the Foundation." In Truth, Thought, and Reason: Essays on Frege, 317-356. Oxford: Oxford University Press. 2005.

Carl, Wolfgang. 1994. Frege's Theory of Sense and Reference: It's Origins and Scope. Cambridge: Cambridge University Press.

Carnap, Rudolf. 1937. The Logical Syntax of Language. Trans Smeaton. London: Routledge.

- - 1950 "Empiricism, Semantics, and Ontology." Revue Internationale de Philosophie 4: $20-40$.

Cohen, Hermann. 1871. Kants Theorie der Erfahrung. 1st Edition. Berlin: Dümmler.

--- 1885. Kants Theorie der Erfahrung. 2nd Edition. Berlin: Dümmler.

Conant, James. 1991. “The Search for Logically Alien Thought.” Philosophical Topics 20: 115-180.

Currie, Gregory. 1987. "Remarks on Frege's Conception of Inference." Notre Dame fournal of Formal Logic 28: 55-68.

de Jong, Willem, and Betti, Arianna. 2010. "The Classical Model of Science: a millenniaold model of scientific rationality." Synthese 174: 185-203.

Elgin, Catherine. 2006. "From Knowledge to Understanding." In Epistemology Futures. ed. Hetherington. Oxford: Oxford University Press.

Field, Hartry. 2015. "What is Logical Validity?” In Foundations of Logical Consequence. ed. Caret and Hjortland. Oxford: Oxford University Press.

Frege, Gottlob. 1874. "Methods of Calculation based on an Extension of the Concept of Quantity.” In Frege 1984, 56-94. Trans. Kaal.

--— 1879-1891. "Logic." In Frege 1979, 1-8.

-- 1879. Begriffsschrift. In From Frege to Gödel, ed. van Heijenoort, 1-83. Harvard University Press, 1967.

-- 1880. "Review of Hoppe, Lehrbuch der anaytischen Geometrie I." In Frege 1984, 101-102. Trans. Kaal.

- - 1880-1881. "Boole's logical Calculus and the Concept-script." In Frege 1979, 9-46,

- - 1882. "Frege to Marty 29.8.1882." In Philosophical and Mathematical Correspondence, Trans. Hans Kaal, ed. Gottfried Gabriel, Hans Hermes, Friedrich Kambartel, Christian Thiel, and Albert Veraart, 112-117. Oxford: Basil Blackwell, 1980.

--_ 1884. Grundlagen Der Arithmetik. Breslau: Wilhelm Koebner Verlag.

--_ 1885a. “On Formal Theories of Arithmetic.” In Frege 1984, 112-121. Tras. Kluge. 
--- 1885b. "Rezension von: H. Cohen, Das Prinzip der Infinitesimal-Methode und seine Geschichte." Zeitschrift für Philosophie und philosophische Kritik 87:324-329

--_ 1891. "Function and Concept." In Frege 1984, 137-156. Trans. Geach.

-_- 1892. "Über Sinn und Bedeutung." Zeitschrift für Philosophie und Philosophische Kritik, 100: 25-50.

--- 1893. Basic Laws of Arithmetic, volume I. In Frege 1967. Trans. Furth.

--_ 1895. “A Critical Elucidation of some Points in E. Schröder's, Vorlesungen über die Algebra der Logik." In Frege 1984, 210-228. Trans. Geach.

--_ 1896. "Frege to Peano 29.9. 1896." In Philosophical and Mathematical Correspondence, Trans. Kaal. Ed. Gabriel, Hermes, Kambartel, Thiel, and Veraart, 112-117. Oxford: Basil Blackwell, 1980.

--_ 1897a. "Logic." In Frege 1979, 126-151.

--- 1897b. "On Mr. Peano's Conceptual Notation and My Own," In Frege 1984, 234248. Trans. Dudman.

-_- 1914. "Logic in Mathematics." In Frege 1979, 203-250.

--- 1918-1919a. "Thoughts." In Frege 1984, 351-372. Trans. Geach and Stoothoff.'

--_ 1918-1919b. "Negation." In Frege 1984, 373-389. Trans. Geach and Stoothoff.'

--_ 1924/1925a. "Sources of Knowledge in Mathematics and the Mathematical Natural Sciences." In Frege 1979, 267-274. Trans. Long and White.

- - 1924/1925b. "A new attempt at a Foundation for Arithmetic." In Frege 1979, 278281. Trans. Long and White.

--- 1967. The Basic Laws of Arithmetic: Exposition of the System. Berkeley: University of California Press.

--- 1979. Posthumous Writings. ed. Hermes, Kambartel and Kaulbach. Oxford: Blackwell.

--- 1984. Collected Papers. ed. Brian McGuinness. Oxford: Basil Blackwell.

Friedman, Michael. 1974. "Explanation and Scientific Understanding." The fournal of Philosophy 71: 5-19.

--- 2000. A Parting of the Ways. Peru: Open Court.

Gabriel, Gottfried. 2002. "Frege, Lotze, and the Continental Roots of Analytic Philosophy." In From Frege to Wittgenstein., ed. Erich Reck, 39-51. Oxford University Press, 2002.

--- 2013. "Truth, Value, and Truth-Value. Frege's Theory of Judgement and its Historical Background." In Fudgement and Truth in Early Analytic Philosophy and Phenomenology, ed. Textor, 36-51. London: Palgrave Macmillan. 
Glock, Hans-Johann. 2015. "Neo-Kantianism and Analytic Philosophy." In New Approaches to Neo-Kantianism., de Warren and Staiti eds., 59-81. Cambridge: Cambridge University Press.

Goldfarb, Warren. 2001. "Frege's Conception of Logic." In The Cambridge Companion to Frege, ed. Potter and Ricketts, 63-85. Cambridge: Cambridge University Press, 2010 .

Grimm, Stephen. 2012. "The Value of Understanding.” Philosophy Compass 7: 103-117.

Heck, Richard G. Jr. 1993. "The Development of Arithmetic in Frege's Grundgesetze der Arithmetik." The fournal of Symbolic Logic 58: 579-601.

- - 2012. Reading Frege’s Grundgesetze. Oxford: Oxford University Press.

Heis, Jeremy. 2013. "Frege, Lotze, and Boole." In The Historical Turn in Analytic Philosophy, 113-138. Ed. Reck. London: Macmillan. 2013.

Jeshion, Robin. 2001. “Frege’s Notions of Self-Evidence.” Mind 110: 937-976.

Kant, Immanuel. 1781/1787. Critique of Pure Reason. Trans. Norman Kemp Smith. London: MacMillan and Co, 1929.

- - 1786. Metaphysical Foundations of Natural Science. Trans. Friedman. Cambridge: Cambridge University Press. 2004.

Kitcher, Philip. 1989. "Explanatory Unifiation and the Causal Structure of the World." Minnesota Studies in the Philosophy of Science 13: 410-505.

Kremer, Michael. 2000. "Judgement and Truth in Frege." Journal of the History of Philosophy 38: 549-581.

Kvanvig, Jonathan. 2003. The Value of Knowledge and the Pursuit of Understanding. Cambridge: Cambridge University Press.

Linnebo, Øystein. 2003. "Frege's Conception of Logic: From Kant to Grundgesetze." Manuscrito 26: 235-252.

Lotze, Hermann. 1874. Logic. Trans. Bosanquet. Oxford: Clarendon. 1884.

---. 1879. Metaphysics, in three books: Ontology, Cosmology, and Psychology. Trans. Bosanquet. Oxford: Oxford University Press. 2nd Edition, 1887.

Macbeth, Danielle. 2005. Frege's Logic. Cambridge: Harvard University Press.

MacFarlane, John. 2000. What Does It Mean To Say That Logic is Formal? Ph.D Dissertation. Pittsburgh: Unviersity of Pittsburgh.

-- 2002. "Frege, Kant, and the Logic in Logicism." Philosophical Review 111, 25-65.

May, Robert. 2018. "Logic as Science." In Eva Picardi on Language, Analysis, and History. ed. Coliva, Leonardi, and Moruzzi. 113-160. London: Palgrave Macmillan. 
Mezzadri, Daniele. 2018. "Formality of Logic and Frege's Begriffsschrift." Canadian fournal of Philosophy, DOI: 10.1080/00455091.2018.1516973

Parsons, Charles. 1986. "Quine on the Philosophy of Mathematics." In The Philosophy of W.V. Quine, ed. Hahn and Schlipp, 369-395. Peru: Open Court. 1986.

Pritchard, Duncan. 2009. "Knowledge, Understanding, and Epistemic Value." Royal Institute of Philosophy Supplement 64: 19-43.

Quine, Willard van Orman. 1960. “Carnap on Logical Truth.” Synthese 12: 350-374.

- - 1986. "Reply to Charles Parsons," In The Philosophy of W.V. Quine, ed. Hahn and Schlipp, 396-404. Peru: Open Court. 1986.

Ricketts, Thomas. 1985. "Frege, the Tractatus, and the Logocentric Predicament." Nô̂s 19: 3-15.

-- 1996. "Logic and Truth in Frege." Proceedings of the Aristotelian Society, Supplementary Volumes 70: 121-175.

--_ 1997. "Frege’s 1906 Foray into Metalogic.” Philosophical Topics 25: 169-188.

Shapiro, Stewart. 2009. "We Hold These Truths To Be Self-Evident: But What Do We Mean By That?" The Review of Symbolic Logic 2: 175-207.

Sluga, Hans. 1997. "Frege on Meaning." In The Rise of Analytic Philosophy, ed. Glock. Oxford: Blackwell. 1997.

Steinberger, Florian. 2016. "The Normative Status of Logic." At the Stanford Encyclopedia of Philosophy. https://plato.stanford.edu/entries/logic-normative.

--- 2017. "Frege and Carnap on the Normativity of Logic." Synthese 194: 143-162.

Tappenden, Jamie. 1997. "Metatheory and Mathematical Practice in Frege." Philosophical Topics 25: 213-264.

Taschek, William. 2008. "Truth, Assertion, and the Horizontal.” Mind 117: 375-401.

Thomas, Reverend Evan Edward. 1921. Lotze's Theory of Reality. London: Longmans, Green, and Co.

Tolley, "The Generality of Kant's Trasncendental Logic." Journal of the History of Philosophy 50: 417-446.

Weiner, Joan. 1996. "Has Frege a Philosophy of Language," In Early Analytic Philosophy: Frege, Russell, Wittgenstein. Ed. Tait. 249-272. Open Court, 1997.

- - 2010. "Understanding Frege's Project." in The Cambridge Companion to Frege, ed. Potter and Ricketts, 32-62. Cambridge: Cambridge University Press. 2010.

Windelband, Wilhelm. 1883 "Kritische oder genetische Methode?" In Präludien, 318354. Tübingen: Mohr Verlag. 1907. 
Zagzebski, Linda. 2001. "Recovering Understanding." In Knowledge, Truth, and Duty: Essays on Epistemic Fustification, Responsibility, and Virtue. ed. Steup. Oxford: Oxford University Press. 